\title{
Combined metformin-associated lactic acidosis and euglycemic ketoacidosis
}

\author{
Verena Schwetz · Florian Eisner • Gernot Schilcher · Kathrin Eller • Johannes Plank · Alice Lind • \\ Thomas R. Pieber · Julia K. Mader · Philipp Eller
}

Received: 26 April 2016 / Accepted: 4 August 2017 / Published online: 1 September 2017

(C) The Author(s) 2017. This article is an open access publication.

\begin{abstract}
Summary
Background In renal failure metformin can lead to lactic acidosis. Additional inhibition of hepatic gluconeogenesis by accumulation of the drug may aggravate fasting-induced ketoacidosis. We report the occurrence of metformin-associated lactic acidosis (MALA) with concurrent euglycemic ketoacidosis (MALKA) in three patients with renal failure.

Case presentations Patient 1: a 78-year-old woman $(\mathrm{pH}=6.89$, lactic acid $22 \mathrm{mmol} / \mathrm{l}$, serum ketoacids $7.4 \mathrm{mmol} / \mathrm{l}$ and blood glucose $63 \mathrm{mg} / \mathrm{dl}$ ) on metformin and insulin treatment. Patient 2: a 79-yearold woman on metformin treatment $(\mathrm{pH}=6.80$, lactic acid $14.7 \mathrm{mmol} / \mathrm{l}$, serum ketoacids $6.4 \mathrm{mmol} / \mathrm{l}$ and blood glucose $76 \mathrm{mg} / \mathrm{dl}$ ). Patient 3: a 71-year-old man on metformin, canagliflozin and liraglutide treatment
\end{abstract}

\section{Author contributions}

V. Schwetz, J.K. Mader, P. Eller collected data, interpreted

data and drafted the manuscript. F. Eisner, G. Schilcher,

K. Eller, J. Plank, A. Lind, T.R. Pieber interpreted data,

contributed to discussions, and critically revised the

manuscript. All authors approved the final version of the manuscript. P. Eller is the guarantor of this work.

V. Schwetz $\cdot$ A. Lind $\cdot$ T. R. Pieber $\cdot$ J. K. Mader $(\bowtie)$

Department of Internal Medicine, Division of

Endocrinology and Diabetology, Medical University of Graz,

Auenbruggerplatz 15, 8036 Graz, Austria

julia.mader@medunigraz.at

F. Eisner · G. Schilcher $\cdot$ P. Eller

Department of Internal Medicine, Intensive Care Unit,

Medical University of Graz, Graz, Austria

\section{K. Eller}

Division of Nephrology, Department of Internal Medicine, Graz, Austria

\section{J. Plank}

Division of Gastroenterology and Hepatology, Department of Internal Medicine, Graz, Austria
$(\mathrm{pH}=7.21$, lactic acid $5.9 \mathrm{mmol} / \mathrm{l}$, serum ketoacids $16 \mathrm{mmol} / \mathrm{l}$ and blood glucose $150 \mathrm{mg} / \mathrm{dl}$ ). In all patients, ketoacidosis receded on glucose infusion and renal replacement therapy.

Conclusion This case series highlights the parallel occurrence of MALA and euglycemic ketoacidosis, the latter exceeding ketosis due to starvation, suggesting a metformin-triggered inhibition of gluconeogenesis. Affected patients benefit from glucose infusion counteracting suppressed hepatic gluconeogenesis.

Keywords Ketoacidosis · Type 2 diabetes · Metformin • Lactic acidosis

\section{Abbreviations}

MALA

MALKA dosis with concurrent euglycemic ketoacidosis

Metformin-associated lactic acidosis with euglycemic ketoacidosis

CKD Chronic kidney disease

ED Emergency department

HR Heart rate

SGLT2 inhibitor Sodium-dependent glucose transporter 2 inhibitor

\section{Background}

Metformin is the most commonly used oral antihyperglycemic drug in type 2 diabetes. Metformin-associated lactic acidosis (MALA) is a rare but severe adverse effect in patients with renal failure. Besides elevation of lactate, acidosis has been attributed to uremia. In severe cases hemodialysis is recommended. Metformin increases the activity of AMP-dependent protein kinase, stimulating fatty acid oxidation, glucose uptake, non-oxidative metabolism, and reducing 
lipogenesis and gluconeogenesis [1], resulting in diminished hepatic glucose production and lower blood glucose levels. In an experimental setting, administration of metformin increased ketoacid production [2]. In renal failure and MALA, accumulation of metformin may lead to increased ketogenesis adding to the acid disturbance.

In this article we report three cases of metforminassociated lactic acidosis and euglycemic ketoacidosis (MALKA), diabetes and acute renal failure identified in 2015 at the intensive care unit (ICU) of a tertiary center. Serum beta-hydroxybutyrate levels $(0.0-8.0 \mathrm{mmol} / \mathrm{l})$ were measured by Precision Xtra Blood $\beta$-Ketone Test Strips (Abbott Diabetes Care, Witney, UK).

\section{Case series}

Patient 1: a 78-year-old woman with a body mass index (BMI) of $26.3 \mathrm{~kg} / \mathrm{m}^{2}$ on metformin and insulin therapy with chronic kidney disease (CKD) stage IIIa due to traumatic unilateral nephrectomy was admitted to the emergency department (ED) with nausea, vomiting, acute on chronic renal failure (creatinine $796.5 \mu \mathrm{mol} / \mathrm{l}$, blood urea nitrogen $28.4 \mathrm{mmol} / \mathrm{l}$ ) and metabolic acidosis with Kussmaul breathing $(\mathrm{pH}=$ 6.89, $\mathrm{HCO}_{3}=5 \mathrm{mmol} / \mathrm{l}, \mathrm{pCO}_{2}=17.3 \mathrm{~mm} \mathrm{Hg}$ or $2.3 \mathrm{kPa}$ ). The premedication included metformin $850 \mathrm{mg}$ b.i. d. and biphasic insulin aspart b.i.d. (16-0-12 IU). On admission to the ICU, the patient was somnolent, the blood pressure (BP) was $103 / 45 \mathrm{~mm} \mathrm{Hg}$, body temperature $34.1^{\circ} \mathrm{C}$, oxygen saturation $97 \%$, heart rate (HR) $76 / \mathrm{min}$, arterial $\mathrm{pO}_{2} 132 \mathrm{~mm} \mathrm{Hg}(=17.6 \mathrm{kPa})$, base excess $-30 \mathrm{mmol} / \mathrm{l}$, anion gap $47 \mathrm{mmol} / \mathrm{l}$ and serum lactic acid level $22 \mathrm{mmol} / \mathrm{l}$. Moreover, the patient displayed elevated serum ketoacids of $7.4 \mathrm{mmol} / \mathrm{l}$ and blood glucose (BG) levels of $63 \mathrm{mg} / \mathrm{dl}$. Labora- tory findings were as follows: C-peptide $0.8 \mathrm{ng} / \mathrm{ml}$ (0.78-1.89), tyrosine phosphatase antibodies $0.0 \mathrm{U} / \mathrm{ml}$ (0.0-20.0), glutamic acid decarboxylase antibodies $0.3 \mathrm{U} / 1(0.0-9.5)$. Cranial computed tomography scan and chest X-ray showed no pathologies. Initial treatment included hemodialysis, bicarbonate substitution, and glucose infusion. The high anion gap acidosis slowly receded during the following days (Fig. 1a). After initial stabilization, the patient acquired pneumonia requiring invasive mechanical ventilation and ongoing renal replacement therapy but finally passed away.

Patient 2: a 79-year-old woman (BMI $28.4 \mathrm{~kg} / \mathrm{m}^{2}$ ) on metformin therapy with previous CKD IIIb on metformin $1000 \mathrm{mg}$ b.i.d., candesartan, gabapentin, phenprocoumon, and pantoprazol was admitted to our ED. She had gastroenteritis with acute on chronic renal failure (creatinine: $796.5 \mu \mathrm{mol} / \mathrm{l}$, blood urea nitrogen: $27.6 \mathrm{mmol} / \mathrm{l}$ ), overt hyperkalemia of $7.7 \mathrm{mmol} / \mathrm{l}$ and metabolic acidosis with Kussmaul breathing $\left(\mathrm{pH}=6.80, \mathrm{HCO}_{3}=5 \mathrm{mmol} / \mathrm{l}, \mathrm{pCO}_{2}=\right.$ $23 \mathrm{~mm} \mathrm{Hg}$ or $3.1 \mathrm{kPa}$ ). On admission to the ICU, she had a BP of $165 / 71 \mathrm{~mm} \mathrm{Hg}$, a HR of $85 / \mathrm{min}$, an oxygen saturation of $98 \%$, a body temperature of $36.8^{\circ} \mathrm{C}$, an arterial $\mathrm{pO}_{2}$ of $175 \mathrm{~mm} \mathrm{Hg}(23.3 \mathrm{kPa})$, a base excess of $-27 \mathrm{mmol} / \mathrm{l}$, and an anion gap of $25 \mathrm{mmol} / \mathrm{l}$. The initial lactic acid level was $16 \mathrm{mmol} / \mathrm{l}$. Moreover, the patient displayed elevated serum ketoacids of $6.4 \mathrm{mmol} / \mathrm{l}$ and a BG of $76 \mathrm{mg} / \mathrm{dl}$. Diabetes-related laboratory findings were indicative of type 2 diabetes: C-peptide $2.34 \mathrm{ng} / \mathrm{ml}$ (0.78-1.89), insulin antibodies $1.0 \mathrm{U} / \mathrm{ml}(0.0-9.0)$, tyrosine phosphatase antibodies $0.0 \mathrm{U} / \mathrm{ml}(0.0-20.0)$, glutamic acid decarboxylase antibodies $2.2 \mathrm{U} / \mathrm{l}(0.0-9.5)$. Chest X-ray on admission was normal. Hemodialysis and parenteral glucose infusion was started and metabolic acidosis thus receded over time (Fig. 1b). Renal function slowly recovered,

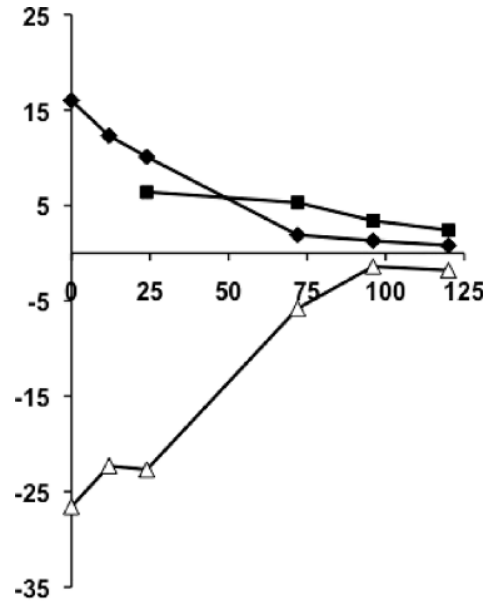

Fig. 1 Metformin-associated lactic acidosis and euglycemic ketoacidosis in three critically ill patients. Blood gas analyses with serum levels of lactic acid (closed diamonds), ketoacids (0.00-8.00 mmol/l; closed squares), and base excess levels

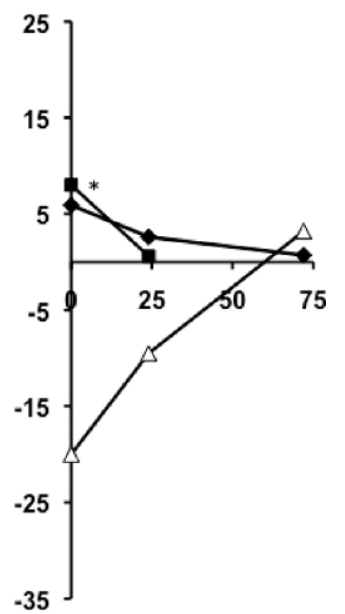

(open triangles) are plotted for patient 1 (a), patient 2 (b), and patient 3 (c) as a function of time $(\mathrm{h})$ on the abscissa. * Ketoacid levels exceeded $8 \mathrm{mmol} / \mathrm{l}$ in this patient, the true value was beyond the range of measurement 
the patient was switched to an insulin regimen and discharged after 14 days.

Patient 3: a 71-year-old man (BMI $30.0 \mathrm{~kg} / \mathrm{m}^{2}$ ) on metformin, canagliflozin, liraglutide, enalapril, allopurinol, pantoprazole and torasemid presented to the ED because of acute gastroenteritis lasting for 6 days. The laboratory analyses revealed acute renal failure (creatinine $1203 \mu \mathrm{mol} / \mathrm{l}$, blood urea nitrogen $36.9 \mathrm{mmol} / \mathrm{l}$ ) and metabolic acidosis with hyperventilation $\left(\mathrm{pH}=7.16, \mathrm{HCO}_{3}=10 \mathrm{mmol} / \mathrm{l}, \mathrm{pCO}_{2}=\right.$ $20 \mathrm{~mm} \mathrm{Hg}$ or $2.7 \mathrm{kPa}$ ). On admission, the $\mathrm{BP}$ was $111 / 38 \mathrm{~mm} \mathrm{Hg}, \mathrm{HR} 73 / \mathrm{min}$, oxygen saturation $98 \%$, body temperature $35.8^{\circ} \mathrm{C}$, arterial $\mathrm{pO}_{2} 88 \mathrm{~mm} \mathrm{Hg}$ $(11.7 \mathrm{kPa})$, base excess $-20 \mathrm{mmol} / \mathrm{l}$, and the anion gap was $21.6 \mathrm{mmol} / \mathrm{l}$. The initial lactic acid level was $5.9 \mathrm{mmol} / \mathrm{l}$, serum ketoacids were $\geq 8 \mathrm{mmol} / \mathrm{l}$ at a blood glucose level of $150 \mathrm{mg} / \mathrm{dl}$. Abdominal sonography and chest X-ray revealed no pathologies. Continuous venovenous hemofiltration was started and parenteral glucose infusion initiated. Metabolic acidosis receded (Fig. 1c) and renal function slowly recovered. The patient was discharged after 9 days.

\section{Conclusion}

To conclude, we report on three critically ill patients with MALKA with metformin accumulation due to acute renal failure. The concurrent occurrence of lactic acidosis and ketoacidosis was reflected in an augmented anion gap. The underlying mechanism contributing to ketoacidosis-aggravated metabolic acidosis could be starvation; however, ketoacid production for alternative energy during starvation usually induces mild metabolic acidosis [3]. Beta-hydroxybutyrate levels in starvation [3] undercut the levels measured in our patients. In the cases presented, metformin-induced inhibition of gluconeogenesis and stimulation of fatty acid oxidation is a likely cofactor for ketogenesis in the absence of other known ketogenic situations, such as pregnancy [4, 5] or alcohol intake [5].

To the best of our knowledge, in the studies published on MALA, ketoacids have not been systematically measured and the anion gap was explained solely by lactate and uremia. In support of our postulated hypothesis of suppressed hepatic gluconeogenesis in MALA leading to euglycemic ketoacidosis, a study in rats has shown the induction of ketoacid production by metformin treatment [2]. Likewise, post-mortem biochemistry analysis of beta-hydroxybutyrate and glucose of the previously mentioned fatal case with metformin overdosing [6] supports our findings.

The mechanism of metformin-associated ketogenesis seems to differ from lack of insulin in type 1 diabetes. Parenteral glucose terminates starvation ketoacidosis and counteracts the suppressed hepatic gluconeogenesis in MALKA. Accordingly, patients with MALKA seem to benefit primarily from parenteral glucose infusion, reflected in a case report of starvation metabolic acidosis [7] and the management of euglycemic ketoacidosis in pregnancy [4]. Interestingly, new evidence suggests that SGLT2-inhibitors might also cause euglycemic ketoacidosis [8]. As the third patient was on canagliflozin and metformin treatment, discrimination of the cause of euglycemic ketoacidosis, i.e. SGLT2 inhibitor and/or biguanide therapy, is currently impossible in that patient.

Taken together, our case series highlights the parallel occurrence of MALA and euglycemic ketoacidosis, the latter exceeding ketosis observed during starvation, suggesting a metformin-triggered inhibition of gluconeogenesis. The occurrence of MALA should prompt investigations for euglycemic ketoacidosis, and euglycemic ketoacidosis should lead to measurement of serum lactate levels in patients on metformin. Furthermore, prospective studies need to clarify the importance of early implementation of glucose infusions in cases of MALKA.

Funding This research did not receive any funding from the public or commercial sector.

\section{Compliance with ethical guidelines}

Conflict of interest V. Schwetz, F. Eisner, G. Schilcher, K. Eller, J. Plank, A. Lind, T.R. Pieber, J.K. Mader, and P. Eller declare that they have no competing interests.

Ethical standards All procedures performed in studies involving human participants were in accordance with the ethical standards of the institutional and/or national research committee and with the 1964 Helsinki declaration and its later amendments or comparable ethical standards. Informed consent was obtained from all individual participants included in the study.

Open Access This article is distributed under the terms of the Creative Commons Attribution 4.0 International License (http://creativecommons.org/licenses/by/4.0/), which permits unrestricted use, distribution, and reproduction in any medium, provided you give appropriate credit to the original author(s) and the source, provide a link to the Creative Commons license, and indicate if changes were made.

\section{References}

1. Shaw RJ, Lamia KA, Vasquez D, et al. The kinase LKB1 mediates glucose homeostasis in liver and therapeutic effects of metformin. Science. 2005;310:1642-6.

2. Tessari P, Tiengo A. Metformin treatment of rats with diet-induced overweight and hypertriglyceridemia decreases plasma triglyceride concentrations, while decreasing triglyceride and increasing ketone body output by the isolated perfused liver. Acta Diabetol. 2008;45:143-5.

3. Owen OE, Smalley KJ, D’Alessio DA, Mozzoli MA, Dawson EK. Protein, fat, and carbohydrate requirements during starvation: anaplerosis and cataplerosis. Am J Clin Nutr. 1998;68:12-34.

4. Frise CJ, Mackillop L, Joash K, Williamson C. Starvation ketoacidosis in pregnancy. Eur J Obstet Gynecol Reprod Biol. 2013;167:1-7.

5. McGuire LC, CruickshankAM, Munro PT.Alcoholicketoacidosis. Emerg Med J. 2006;23:417-20. 
6. Bonsignore A, Pozzi F, Fraternali Orcioni G, Ventura F, Palmiere C. Fatal metformin overdose: case report and postmortem biochemistry contribution. Int J Legal Med. 2014;128:483-92.

7. Toth HL, Greenbaum LA. Severe acidosis caused by starvation and stress. Am J Kidney Dis. 2003;42:E16-E9.
8. Peters AL, Buschur EO, Buse JB, Cohan P, Diner JC, Hirsch IB. Euglycemic diabetic ketoacidosis: a potential complication of treatment with sodium-glucose cotransporter 2 inhibition. Diabetes Care. 2015;38:1687-93. 